\title{
Karakterisasi Suseptibilitas Magnet Barium Ferit yang Disintesis dari Pasir Besi dan Barium Karbonat Menggunakan Metode Metalurgi Serbuk
}

\author{
Rahmatil Hayati*, Arif Budiman, Dwi Puryanti \\ Jurusan Fisika Universitas Andalas \\ *yatrahmatil93@gmail.com
}

\begin{abstract}
ABSTRAK
Telah dilakukan penelitian tentang karakterisasi suseptibiltas magnet barium ferit yang disintesis dari pasir besi dan barium karbonat menggunakan metode metalurgi serbuk. Pasir besi diperoleh dari Sungai Sukam, Kabupaten Sijunjung, Sumatera Barat. Magnet barium ferit dibuat dengan mencampurkan $\mathrm{Fe}_{2} \mathrm{O}_{3}$ hasil oksidasi magnetit pasir besi dan $\mathrm{BaCO}_{3}$. Kemudian campuran tersebut dikalsinasi pada suhu 1000 ${ }^{\circ} \mathrm{C}$, lalu dikompaksi dan kemudian disintering pada temperatur $1000{ }^{\circ} \mathrm{C}$. Karakterisasi magnet barium ferit dilakukan dengan mengukur suseptibilitas magnetik menggunakan Bartington MS2 Magnetic susceptibility meter. Hasil penelitian ini menunjukkan nilai suseptibilitas yang diperoleh dari enam variasi persentase massa yaitu $5,10,15,20,25$ dan $30 \%$ berturut-turut adalah $262,6 \times 10^{-8}, 438,0 \times 10^{-8}$, $516,1 \times 10^{-8}, 549,9 \times 10^{-8}, 422,8 \times 10^{-8}$ dan $429,9 \times 10^{-8} \mathrm{~m}^{3} / \mathrm{kg}$. Dengan nilai suseptibilitas tertinggi pada persentase massa $20 \%$ sebesar $549,9 \times 10^{-8} \mathrm{~m}^{3} / \mathrm{kg}$. Tingginya nilai suseptibilitas dikarenakan ion $\mathrm{Fe}^{3+}$ yang seimbang pada komposisi barium ferit. Nilai suseptibilitas magnetik barium ferit naik dengan kenaikan persentase massa $\mathrm{BaCO}_{3} 5$ hingga 20\%, dan menurun untuk persentase massa $\mathrm{BaCO}_{3}$ besar dari $20 \%$.

Kata kunci: barium ferit, barium karbonat, pasir besi, suseptibilitas
\end{abstract}

\begin{abstract}
The research on the characterization of susceptibility of barium ferrite magnets synthesized from iron sand and barium carbonate using powder metallurgy method has been done. Iron sand was obtained from the River Sukam, Sijunjung district, West Sumatra. Iron sand was obtained from River Sukam, Sijunjung district, West Sumatera. Barium ferrite magnet was made by mixing $\mathrm{Fe}_{2} \mathrm{O}_{3}$ magnetite oxidation results and $\mathrm{BaCO}_{3}$. Then, the mixture was calcinated at $1000^{\circ} \mathrm{C}$, then compacted and sintered at $1000^{\circ} \mathrm{C}$ temperature. Characterization of barium ferrite magnet was done by measuring magnetic susceptibility using Bartington MS2 Magnetic Susceptibility Meter. Results show that susceptibility of the sample with six variations of the mass percentage 5, 10, 15, 20, 25 and $30 \%$ respectively are $262,6 \times 10^{-8}, 438,0 \times 10^{-8}$, $516,1 \times 10^{-8}, 549,9 \times 10^{-8}, 422,8 \times 10^{-8}$ and $429,9 \times 10^{-8} \mathrm{~m}^{3} / \mathrm{kg}$. The high value of susceptibility is $549,9 \times 10^{-8}$ $\mathrm{m}^{3} / \mathrm{kg}$ at sample with $20 \%$ mass percentage. The value of susceptibility was high because Fe ${ }^{3+}$ of ion was balance in the composition of barium ferrite. The addition of $\mathrm{BaCO}_{3}$ with mass percentage of 5 to $20 \%$ increase the value of barium ferrite magnetic susceptibility, and start to decrease when mass percentage of $\mathrm{BaCO}_{3}$ larger than $20 \%$.
\end{abstract}

Keywords: barium carbonate, barium ferrite, barium carbonate, susceptibility, iron sand

\section{PENDAHULUAN}

Magnet menjadi bagian yang tidak terpisahkan dari kehidupan manusia masa kini. Mulai dari peralatan listrik sampai dengan peralatan non listrik memanfaatkan magnet tetap. Contohnya loudspekaer, meteran air, KWH-meter, rice cooker, transformer dan generator. Karakterisitik bahan-bahan magnetik ditentukan oleh besaran-besaran magnetik seperti suseptibilitas, magnetisasi remanen, magnetisasi saturasi dan medan koersivitas. Jenis magnet yang sering digunakan adalah magnet ferit. Magnet ferit terdiri dari ferit keras dan ferit lunak. Magnet jenis ini disintesis dengan menggunakan bahan dasar besi oksida yaitu hematit $(\alpha-$ $\mathrm{Fe}_{2} \mathrm{O}_{3}$ ) ditambah dengan zat aditif. Ferit keras menggunakan zat aditif seperti $\mathrm{BaCO}_{3}, \mathrm{SrCO}_{3}$ dan $\mathrm{PbCO}_{3}$ untuk pembuatannya. Sedangkan ferit lunak menggunakan zat aditif berupa $\mathrm{ZnO}$, $\mathrm{MnO}_{2}, \mathrm{MgO}$ dan lain-lain.

Salah satu jenis ferit yang banyak dimanfaatkan adalah barium ferit $\left(\mathrm{BaFe}_{12} \mathrm{O}_{19}\right)$. Pembuatan barium ferit dilakukan dengan pencampuran hematit $\left(\alpha-\mathrm{Fe}_{2} \mathrm{O}_{3}\right)$ dengan barium karbonat $\left(\mathrm{BaCO}_{3}\right)$. Magnet barium ferit mempunyai medan koersivitas yang tinggi dan tahan terhadap korosi. Meskipun karakteristik energinya lebih rendah dibandingkan dengan magnet 
keras lainnya seperti magnet neodymium iron boron $(\mathrm{NdFeB})$, samarium-cobalt $(\mathrm{Sm}-\mathrm{Co})$, dan alnico (Al-Ni-Co), tetapi magnet keras ferit masih banyak digunakan untuk aplikasi magnet permanen karena bahannya yang melimpah dan murah (Irasari dan Idayanti, 2009).

Bahan dasar pembuatan magnet barium ferit adalah hematit $\left(\alpha-\mathrm{Fe}_{2} \mathrm{O}_{3}\right)$ yang didapatkan dari proses oksidasi magnetit $\left(\mathrm{Fe}_{3} \mathrm{O}_{4}\right)$ pada temperatur $700{ }^{\circ} \mathrm{C}$ selama 3 jam yang ditandai dengan perubahan warna menjadi kecoklatan (Basith, dkk, 2012). Magnetit $\left(\mathrm{Fe}_{3} \mathrm{O}_{4}\right)$ banyak terkandung di alam, salah satunya yaitu pasir besi. Dalam pasir besi terkandung beberapa anggota besi oksida, yaitu magnetit $\left(\mathrm{Fe}_{3} \mathrm{O}_{4}\right)$, ilmenite $\left(\mathrm{FeTiO}_{3}\right)$ dan hematit $\left(\alpha-\mathrm{Fe}_{2} \mathrm{O}_{3}\right)$ (Zulkarnain, 2000). Sintesis Barium ferit dari hematit $\left(\alpha-\mathrm{Fe}_{2} \mathrm{O}_{3}\right)$ dan barium karbonat $\left(\mathrm{BaCO}_{3}\right)$ dapat dilakukan menggunakan beberapa metode seperti sol gel, kopresipitasi, pemaduan mekanik, metalurgi serbuk, dan solid state reaction. Metode diatas dipengaruhi oleh persentase campuran bahan, proses kalsinasi, kompaksi dan sintering.

Peneliti sebelumnya yang telah melakukan penelitian yang berhubungan dengan pembuatan magnet barium ferit yaitu Nugraha, dkk (2015). Nugraha, dkk (2015) melakukan penelitian tentang sintesis magnet barium ferit dari pasir besi Pantai Cilacap dan $\mathrm{BaCO}_{3}$ dengan variasi massa $15 \%, 30 \%$ dan $45 \%$. Hasil penelitian menunjukkan bahwa penambahan $\mathrm{BaCO}_{3}$ berpengaruh pada pembentukan multi fasa kristal barium ferit dan memperlebar distribusi ukuran kristalit, serta menurunkan remanensi dan saturasi bahan tersebut. Komposisi terbaik magnet barium ferit diperoleh untuk konsentrasi $\mathrm{BaCO}_{3}$ sebanyak $15 \%$, dengan suseptibilitas massa tertinggi yaitu $2,4 \times 10^{-6} \mathrm{~m}^{3} / \mathrm{kg}$. Oleh karena itu, dalam penelitian ini akan dilakukan karakterisasi magnet barium ferit yang disintesis dari pasir besi dan barium karbonat menggunakan metode metalurgi serbuk, karena lebih mudah dan ekonomis karena tidak ada material yang terbuang selama pembuatan. Pasir besi yang digunakan pada penelitian ini berasal dari sungai Batang Sukam di Kabupaten Sijunjung, Sumatera Barat. Pasir besi ini memiliki mineral magnetik dengan suseptibilitas relatif lebih tinggi dibandingkan dengan mineral magnetik yang berasal dari pasir besi dari pantai (Siregar, 2015). Karakterisasi magnet dilakukan dengan mengukur nilai suseptibilitas menggunakan alat Bartington magnetic susceptibility tipe MS2B.

\section{METODE}

Bahan-bahan yang digunakan yaitu pasir besi, barium karbonat $\left(\mathrm{BaCO}_{3}\right)$, aquades, alkohol, polivinil Alcohol (PVA) dan plasticine atau lilin mainan. Adapun alat yang digunakan adalah Bartington MS2 Magnetic Susceptibility Meter dan sensor MS2B, komputer, magnetic stirrer, alat pencetak tablet, separator magnetik, timbangan digital, ayakan 200 mesh, lumpang dan alu, furnace, gelas ukur $100 \mathrm{ml}$, sample holder dan magnet permanen.

\subsection{Pemisahan Sampel}

Pemisahan sampel dilakukan dalam beberapa tahap yaitu, pertama pasir besi dicuci dengan aquades, kemudian dikeringkan menggunakan oven pada temperatur $4{ }^{\circ} \mathrm{C}$ selama $1 \mathrm{jam}$. Setelah dikeringkan, mineral magnetik dan non-magnetik pasir besi dipisahkan dengan magnet permanen sebanyak 7 kali dan hasilnya digerus selama 2 jam. Pasir besi yang sudah digerus dipisahkan kembali dengan magnet permanen sebanyak 3 kali dan digerus selama 2 jam. Untuk mendapatkan magnetit, hasil penggerusan dipisahkan dengan separator magnetik. Hasilnya kemudian diayak dengan ayakan 200 mesh. Selanjutnya digunakan alat difraktometer sinar-X untuk memastikan bahwa sampel mengandung mineral magnetit.

\subsection{Sintesis Hematit}

Serbuk magnetit yang diperoleh di atas dioksidasi menggunakan furnace pada temperatur $700{ }^{\circ} \mathrm{C}$ selama 3 jam untuk mengubah magnetit menjadi hematit.

\subsection{Sintesis Magnet Barium Ferit}

Sintesis magnet barium feri adalah sebagai berikut: 
1. Hematit $\left(\alpha-\mathrm{Fe}_{2} \mathrm{O}_{3}\right)$ hasil oksidasi dicampur dengan barium karbonat $\left(\mathrm{BaCO}_{3}\right)$. Agar bahan baku tercampur dengan rata, campuran hematit dan barium karbonat digerus menggunakan lumpang, kemudian dilarutkan menggunakan alkohol. Penambahan alkohol yang digunakan dengan persentase $40 \%$ padatan dan $60 \%$ alkohol teknis $96 \%$ dan dipanaskan menggunakan oven dengan temperatur $110{ }^{\circ} \mathrm{C}$ selama 1 jam. Setelah itu hasilnya digerus dengan lumpang agar tidak menggumpal. Pencampuran bahan baku dilakukan dengan variasi persentase massa yang dapat dilihat pada Tabel 1.

Tabel 1 Variasi persentase massa barium ferit

\begin{tabular}{ccc}
\hline $\begin{array}{c}\text { Persentase }(\%) \\
\mathbf{B a C O}_{3}\end{array}$ & $\begin{array}{c}\mathbf{B a C O}_{3} \\
(\mathbf{g r})\end{array}$ & $\begin{array}{c}\boldsymbol{\alpha}-\mathrm{Fe}_{2} \mathbf{O}_{3} \\
(\mathbf{g r})\end{array}$ \\
\hline 5 & 1 & 19 \\
10 & 2 & 18 \\
15 & 3 & 17 \\
20 & 4 & 16 \\
25 & 5 & 15 \\
30 & 6 & 14 \\
\hline
\end{tabular}

2. Campuran $\alpha-\mathrm{Fe}_{2} \mathrm{O}_{3}$ dan $\mathrm{BaCO}_{3}$ kemudian dikalsinasi dalam furnace pada temperatur $1000{ }^{\circ} \mathrm{C}$ ditahan selama 3 jam. Hasil yang diperoleh dari proses kalsinasi berbentuk gumpalan sehingga harus digerus kembali menggunakan lumpang.

3. Serbuk barium ferit hasil kalsinasi dicampur dengan PVA kemudian dibentuk menjadi pelet dengan diameter $1,24 \mathrm{~cm}$ dan ketebalan $0,5 \mathrm{~cm}$.

4. Pelet hasil kompaksi masing-masing variasi campuran bahan baku kemudian disintering dalam furnace pada temperatur $1000{ }^{\circ} \mathrm{C}$ dan setelah mencapai suhu tersebut ditahan selama 2 jam.

\subsection{Pengukuran Suseptibilitas}

Pengukuran nilai suseptibilitas dilakukan menggunakan Bartington MS2 Magnetic Susceptibility Meter menggunakan sensor MS2B dan software multisus. Nilai suseptibilitas dilakukan dengan 15 arah pengukuran dan data diolah menggunakan software MATLAB R2012b dan dapat dilihat pada Gambar 1.

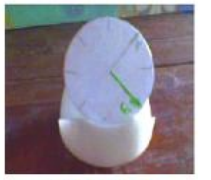

Posisi 1

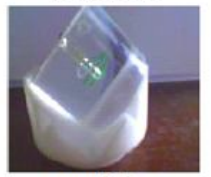

Posisi 6

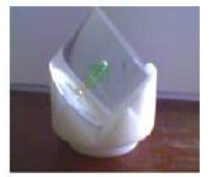

Posisi 11

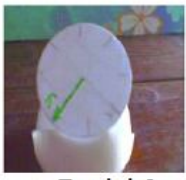

Posisi 2

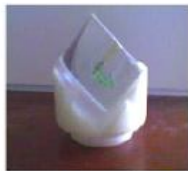

Posisi 7

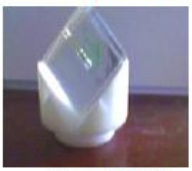

Posisi 12

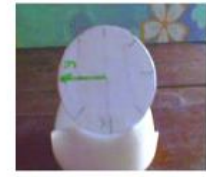

Posisi 3

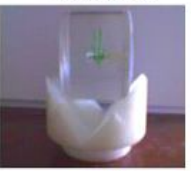

Posisi 8

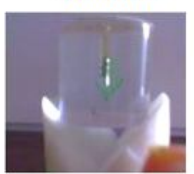

Posisi 13

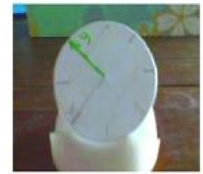

Posisi 4

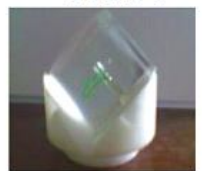

Posisi 9

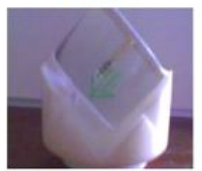

Posisi 14

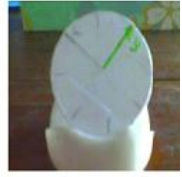

Posisi 5

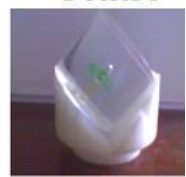

Posisi 10

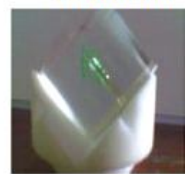

Posisi 15

Gambar 1 Implementasi dari pola putar pengukuran 15 arah

\section{HASIL DAN DISKUSI}

Hasil difraktogram sinar-X sampel dapat dilihat pada Gambar 2. Dari Gambar 2 terlihat bahwa mineral magnetik yang terkandung dalam sampel adalah magnetit. Puncak-puncak energi pada difraktoram terlihatnya hanya puncak-puncak magnetit. Biasanya mineral magnetik 
yang terkandung dalam pasir besi selain magnetit terdapat juga hematit. Hal ini menunjukkan bahwa mineral magnetik pasir besi sungai Batang Sukam di Kabupaten Sijunjung, Sumatera Barat hanya mengandung magnetit. Oleh karena itu diperoleh hasil perhitungan nilai suseptibilitas magnetik mineral magnetik tersebut relatif tinggi yaitu $10971 \times 10^{-8} \mathrm{~m}^{3} / \mathrm{kg}$ (Siregar, 2015).

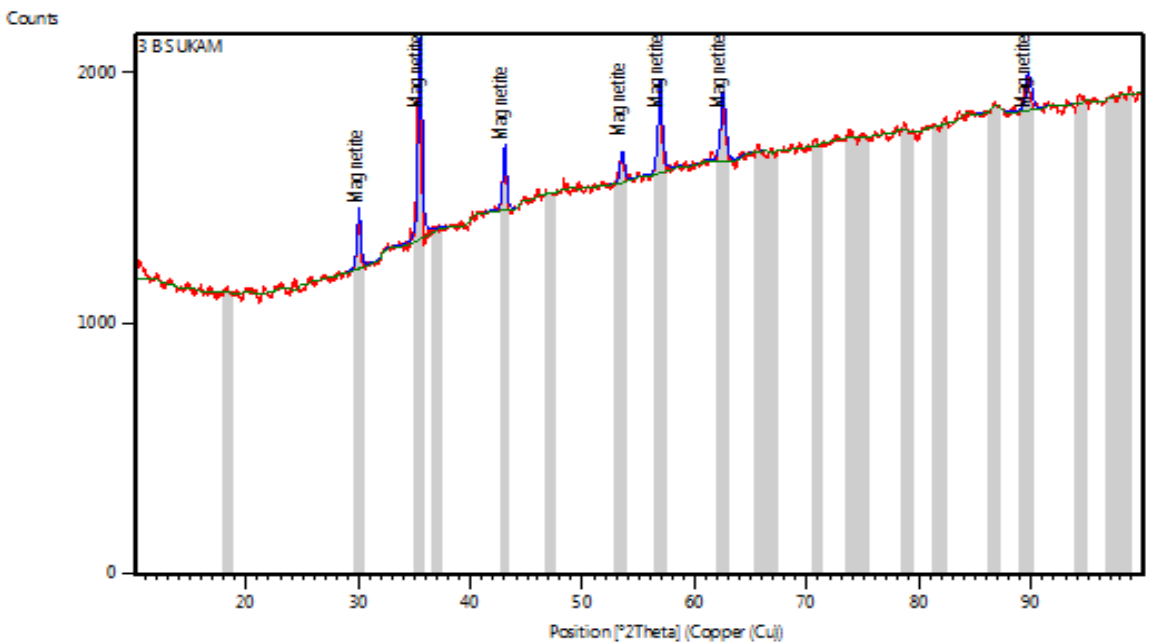

Gambar 2 Hasil difraktometer sinar-X serbuk magnetit

Selanjutnya magnetit dioksidasi menggunakan furnace pada temperatur $700{ }^{\circ} \mathrm{C}$ selama 3 jam sehingga diperoleh serbuk berwarna kecoklatan. Salah satu tanda bahwa hematit telah terbentuk yaitu dengan terjadinya perubahan warna sampel dari hitam sebelum oksidasi menjadi kocoklatan setelah oksidasi. Perubahan warna sampel hasil oksidasi magnetit menjadi hematit tidak diuji menggunakan alat difraktometer sinar-X karena telah dibuktikan oleh beberapa peneliti sebelumnya yaitu Yulianto, dkk (2003), Basith, dkk (2012), Pratapa (2014) dan Kartika, dan Trilismana (2015) yang telah berhasil melakukan oksidasi magnetit mejadi hematit.

Hasil perhitungan nilai suseptibilitas dapat dilihat pada Tabel 2. Pada Tabel 2 untuk massa barium ferit $5 \%$ memiliki nilai suseptibilitas rata-rata $262,6 \times 10^{-8} \mathrm{~m}^{3} / \mathrm{kg}$ dengan nilai suseptibilitas tertinggi $265,7 \times 10^{-8} \mathrm{~m}^{3} / \mathrm{kg}$ pada sampel ke empat dan terendah $249,9 \times 10^{-8} \mathrm{~m}^{3} / \mathrm{kg}$ pada sampel pertama. Sampel ini memiliki nilai suseptibilitas yang rendah dibandingkan dengan sampel yang lain. Pada persentase massa $10 \%$ nilai suseptibilitas berkisar antara $412,1 \times 10^{-8} \mathrm{~m}^{3} / \mathrm{kg}$ sampai dengan $454,6 \times 10^{-8} \mathrm{~m}^{3} / \mathrm{kg}$ dengan nilai rata-rata $438,0 \times 10^{-8} \mathrm{~m}^{3} / \mathrm{kg}$. Nilai suseptibilitas ini lebih tinggi dibandingkan dengan sampel dengan persentase massa $5 \%$.

Tabel 2 Hasil perhitungan nilai suseptibilitas magnetik masing-masing variasi persentase massa barium ferit

\begin{tabular}{ccccccc}
\hline \multirow{2}{*}{$\begin{array}{c}\text { No. } \\
\text { Sampel }\end{array}$} & \multicolumn{5}{c}{ Nilai Suseptibilitas $\left(\times \mathbf{1 0}^{-\mathbf{8}} \mathbf{~ m}^{\mathbf{3}} \mathbf{k g}\right)$} \\
\cline { 2 - 7 } & $\mathbf{5 \%}$ & $\mathbf{1 0 \%}$ & $\mathbf{1 5 \%}$ & $\mathbf{2 0 \%}$ & $\mathbf{2 5 \%}$ & $\mathbf{3 0 \%}$ \\
\cline { 2 - 7 } & 249,9 & 448,8 & 509,7 & 585,2 & 427,2 & 427,0 \\
1 & 251,9 & 423,1 & 506,6 & 560,5 & 434,3 & 417,9 \\
2 & 263,5 & 412,1 & 509,0 & 556,7 & 460,0 & 453,3 \\
3 & 265,7 & 454,6 & 523,4 & 520,0 & 428,2 & 429,7 \\
4 & 282,1 & 451,4 & 531,7 & 527,0 & 464,4 & 421,4 \\
5 & 262,6 & 438,0 & 516,1 & 549,9 & 442,8 & 429,9 \\
\hline Rata-rata & 4,9 & 4,3 & 2,1 & 4,8 & 4,1 & 3,2 \\
\hline KK (\%) & & & & & &
\end{tabular}

Sampel selanjutnya dengan persentase massa bahan baku $\mathrm{Fe}_{2} \mathrm{O}_{3}$ dan $\mathrm{BaCO}_{3} 15 \%$ menghasilkan nilai suseptibilitas yang lebih tinggi dengan rata-rata $516,1 \times 10^{-8} \mathrm{~m}^{3} / \mathrm{kg}$. Dengan nilai suseptibilitas tertinggi pada sampel kelima dengan nilai suseptibilitas $531,7 \times 10^{-8} \mathrm{~m}^{3} / \mathrm{kg}$ dan terendah $506,6 \times 10^{-8} \mathrm{~m}^{3} / \mathrm{kg}$ pada sampel kedua. Nilai suseptibilitas tertinggi terdapat pada 
sampel dengan persentase massa $20 \% \mathrm{Fe}_{2} \mathrm{O}_{3}$ dengan $\mathrm{BaCO}_{3}$, dengan rata-rata $549,9 \times 10^{-8} \mathrm{~m}^{3} / \mathrm{kg}$. Sampel pertama memiliki nilai suseptibilitas tertinggi yaitu $585,2 \times 10^{-8} \mathrm{~m}^{3} / \mathrm{kg}$ dan terendah pada sampel ke lima $527,0 \times 10^{-8} \mathrm{~m}^{3} / \mathrm{kg}$. Sampel dengan persentase massa $25 \%$ memiliki nilai suseptibilitas tertinggi $464,4 \times 10^{-8} \mathrm{~m}^{3} / \mathrm{kg}$ dan terendah $427,2 \times 10^{-8} \mathrm{~m}^{3} / \mathrm{kg}$. Sampel ini memiliki rata-rata suseptibilitas $442,8 \times 10^{-8} \mathrm{~m}^{3} / \mathrm{kg}$. Sedangkan untuk sampel dengan massa $30 \%$, didapatkan nilai suseptibilitas tertinggi sebesar $453,3 \times 10^{-8} \mathrm{~m}^{3} / \mathrm{kg}$ dan terendah $417,9 \times 10^{-8} \mathrm{~m}^{3} / \mathrm{kg}$ dengan suseptibilitas rata-rata $429,9 \times 10^{-8} \mathrm{~m}^{3} / \mathrm{kg}$.

Setiap variasi persentase massa, pengukuran nilai suseptibilitas dilakukan sebanyak lima kali. Kelima masing-masing sampel tersebut memiliki nilai suseptibilitas yang berbedabeda. Dilihat dari nilai koefisien keragaman (KK), penyimpangan terbesar terdapat pada sampel dengan persentase $5 \%$ dengan nilai KK yaitu $4,9 \%$ dan yang terkecil $2,1 \%$ pada sampel dengan persentase $15 \%$. Walaupun memiliki nilai KK yang tinggi, namun nilai tersebut masih dapat digunakan dalam pengukuran fisika karena masih dibawah 5\%. Berdasarkan perhitungan, hubungan nilai suseptibilitas terhadap variasi persentase massa barium ferit dapat dilihat pada Gambar 3.

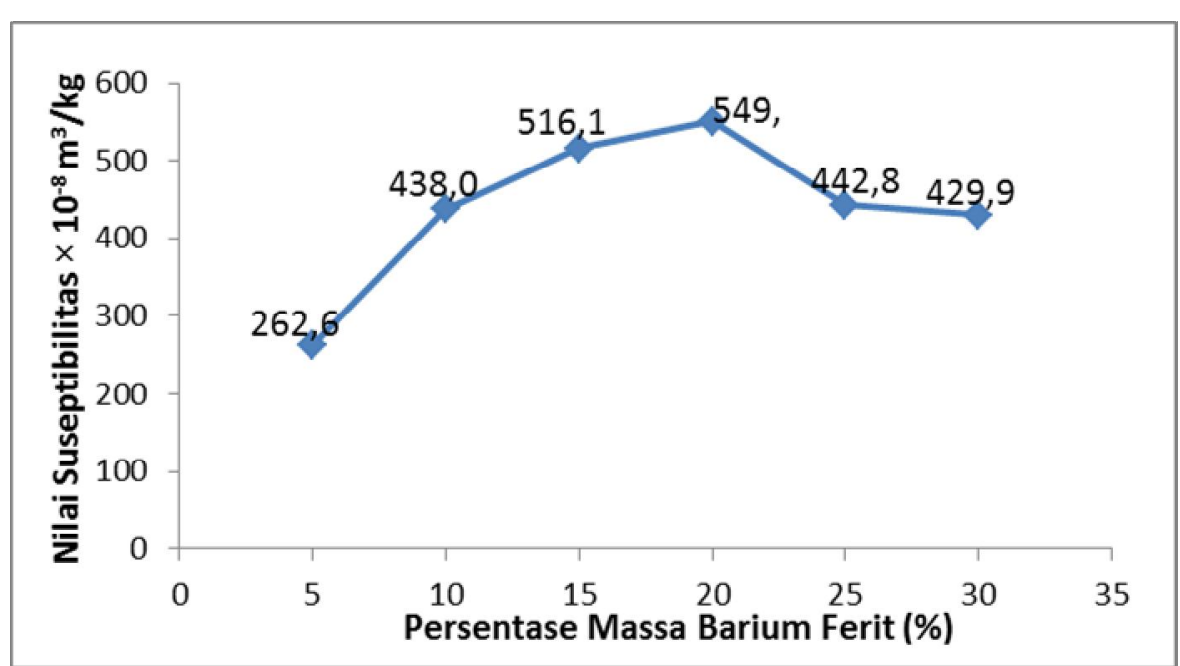

Gambar 3 Grafik hubungan nilai suseptibilitas terhadap variasi magnet barium ferit

Dari Gambar 3 terlihat hubungan nilai suseptibilitas terhadap variasi persentase massa barium ferit, dari persen massa barium ferit 5\% hingga $20 \%$ mengalami kenaikan nilai suseptibilitas. Sedangkan dari persen massa $25 \%$ hingga $30 \%$ terjadi penurunan nilai suseptibilitas. Penurunan ini karena massa $\mathrm{BaCO}_{3}$ yang lebih banyak akibat dari ion $\mathrm{Ba}^{2+}$ sebagai ion non-magnetik lebih banyak daripada ion $\mathrm{Fe}^{3+}$ yang bersifat magnetik. Barium ferit terdiri dari ion $\mathrm{O}^{-2}$, ion $\mathrm{Ba}^{2+}$ dan ion $\mathrm{Fe}^{3+}$. Dalam barium ferit ion $\mathrm{O}^{-2}$, ion $\mathrm{Ba}^{2+}$ jumlah momen magnetnya nol dan hanya ion $\mathrm{Fe}^{3+}$ yang bersifat magnet. Momen magnet dari ion-ion $\mathrm{Fe}^{3+}$ tidak dapat dijumlahkan begitu saja karena arah momen magnet material ferimagnetik adalah antiparalel sehingga tidak bisa dijumlahkan karena tidak dapat saling menghilangkan. Makanya muncul momen magnetik netto yaitu momen yang tidak saling menghilangkan. Momen magnetik netto yang menyebabkan senyawa ferit memiliki magnetisasi permanen tanpa pengaruh medan luar $\mathrm{H}$ (Rohman, 2010). Jika massa $\mathrm{BaCO}_{3}$ bertambah banyak, maka ion $\mathrm{Ba}^{2+}$ melebihi ion $\mathrm{Fe}^{3+}$ sehingga menyebabkan ion yang bersifat magnet pada barium ferit berkurang dan mengakibatkan penurunan nilai suseptibilitas.

Seperti yang disebutkan pada pendahuluan, peneliti sebelumnya (Nugraha, 2015) juga menentukan nilai suseptibilitas magnet barium ferit dan didapatkan nilai suseptibilitas sebesar $240,0 \times 10^{-8} \mathrm{~m}^{3} / \mathrm{kg}$ pada persentase massa $15 \%$. Nilai rata-rata suseptibilitas yang didapatkan pada penelitian ini lebih besar dibandingkan dengan penelitian sebelumnya yaitu sebesar $549,9 \times 10^{-8} \mathrm{~m}^{3} / \mathrm{kg}$ pada massa $20 \%$. Pada penenlitian ini nilai suseptibilitas tertinggi diperoleh pada persentase massa $20 \%$, sedangkan pada penenelitian sebelumnya pada persentase massa $15 \%$. Persentase massa $15 \%$ pada penelitian ini memiliki nilai suseptibilitas yang lebih tinggi 
dari penelitian sebelumnya. Hal ini dikarenakan mineral pasir besi yang digunakan berasal dari hasil pendulangan emas dan memiliki nilai suseptibilitas yang tinggi (Siregar, 2015).

\section{KESIMPULAN}

Berdasarkan hasil pengukuran dan perhitungan nilai suseptibilitas magnet barium ferit dapat disimpulkan bahwa, Nilai suseptibilitas rata-rata yang diperoleh dari persentase massa 5 , $10,15,20,25$ dan $30 \%$ berturut yaitu $262,6 \times 10^{-8}, 438,0 \times 10^{-8}, 516,1 \times 10^{-8}, 549,9 \times 10^{-8}$, $422,8 \times 10^{-8}$ dan $429,9 \times 10^{-8} \mathrm{~m}^{3} / \mathrm{kg}$. Nilai suseptibilitas tertinggi pada persentase massa $20 \%$ yaitu $549,9 \times 10^{-8} \mathrm{~m}^{3} / \mathrm{kg}$. Tingginya nilai suseptibilitas dikarenakan ion $\mathrm{Fe}^{3+}$ yang seimbang pada komposisi barium ferit. Nilai suseptibilitas menurun seiring dengan bertambahnya massa $\mathrm{BaCO}_{3}$ diatas persentase massa barium ferit $20 \%$.

\section{DAFTAR PUSTAKA}

Basith, A., Taufiq, A., Sunaryono dan Darminto, Jurnal Fisika dan Aplikasinya 8, 120205-1 120205-3 (2012).

Irasari, P dan Idayanti, N., Jurnal Sains Material Indonesia 11, 38-41 (2009).

Kartika, L.K dan Pratap, S., Jurnal Sains dan Seni Pomits 3, 33-35 (2014).

Nugraha, P.R., Widanarto, W., Cahyanto, W.T. dan Kuncoro, H.S., Jurnal Berkala Fisika 18, 43-50 (2015).

Rohman, L.H.K.," Fabrikasi dan Karakterisasi Sifat Mekanik Kaca Magnetik Berbasis Barium Ferit", Skripsi S1, Universitas Negeri Semarang, 2010.

Siregar, S., "Penentuan Nilai Suseptibilitas Magnetik Pasir Besi Sisa Pendulangan Emas di Kabupaten Sijunjung Sumatera Barat", Skripsi S1, Universitas Andalas, 2015.

Trilismana, H., Budiman, A., Jurnal Fisika Unand 4, 150-156 (2015).

Yulianto, A., Bijaksan, S., Loeksmanto, W., Kurnia, D., Indonesia Journal of Material Science 5, 51-54 (2003).

Zulkarnain, "Kemungkinan Pemanfaatan Pasir Besi Pesisir Pantai Aceh untuk Fabrikasi Magnet," Prosiding Seminar Nasional Bahan Magnet I, 2000. 